\title{
Sistem Kendali Pintu Perangkat Telekomunikasi Menggunakan Smartphone
}

\section{The Door Control System as Telecommunication Device by Smartphone}

\author{
Jaenal Arifin ${ }^{1, *}$, Faris Radifan Ahmad ${ }^{2}$ \\ ${ }^{1}$ Program Studi Teknik Elektro, ${ }^{2}$ Program Studi D-III Teknik Telekomunikasi \\ Fakultas Telekomunikasi dan Elektro, Institut Teknologi Telkom Purwokerto \\ Jl. D.I.Panjaitan no.128 Purwokerto, Jawa Tengah, Indonesia \\ 1,*Penulis Korespondensi: jaetoga@ittelkom-pwt.ac.id \\ ${ }^{2} 13201014 @$ ittelkom-pwt.ac.id
}

Received on 04-12-2019, accepted on 20-10-2020, published on 30-12-2020

\begin{abstract}
Abstrak
Saat ini smartphone menjadi salah satu kebutuhan yang tidak bisa dipisahkan dari berbagai aktivitas manusia. Terutama smartphone sekarang dengan fiturnya yang dapat berfungsi menggantikan fungsi kunci fisik atau secara manual. Hal tersebut dapat meningkatkan keamanan dalam mengunci ruangan maupun perangkat telekomunikasi. Perangkat MSAN merupakan perangkat telekomunikasi yang dapat mengoptimalkan media akses pada sistem transmisi serat optik. Dalam sistem kendali ini digunakan modul bluetooh HC-05 sebagai media komunikasi untuk melakukan pengendalian jarak jauh dalam membuka pintu melalui aplikasi pada smartphone android. Untuk mengunci pintu digunakan NFC Shield dan NFC tag yang telah terintegrasi dengan mikropengendali Arduino. Arduino UNO berfungsi sebagai pengendali output berupa motor servo (membuka dan mengunci pintu) yang dikombinasikan dengan LED (Light Emitting Diode) sebagai output visual. Pada hasil pengujian pengendalian, komunikasi bluetooth dapat terhubung pada jarak 16 meter tanpa penghalang, dan jika terdapat penghalang hanya pada jarak 8 meter. NFC shield dapat mendeteksi NFC tag secara optimal pada jarak $\mathbf{1}-\mathbf{5} \mathrm{cm}$ dan pada sudut optimal 0-75․ Hasil pengujian keseluruhan komponen sistem kendali dapat berfungsi dengan baik dan berjalan sesuai dengan yang diharapkan.
\end{abstract}

Kata kunci: Arduino, Bluetooth, Kendali pintu, NFC, Smartphone.

\section{Abstract}

Currently, smartphones are necessary and cannot be separated from various human activities. Especially smartphones now with features that can replace the essential physical function manually. This feature can be enriched by applying security in the room locking and telecommunications between equipment. MSAN device is a telecommunications device that can optimize media access in fiber optic transmission systems. In this control system, the HC-05 Bluetooth module is used as a communication medium to remotely control opening doors through an application on an android smartphone. An NFC Shield and NFC tag were used to lock the door, integrated with the Arduino microcontroller. Arduino UNO functions as an output controller in a servo motor (opens and locks the door) combined with an LED (Light Emitting Diode) as a visual output. In the control test results, Bluetooth communication can be connected at a distance of 16 meters without obstructions, and if there are obstacles only at a distance of $\mathbf{8}$ meters. The NFC shield can detect NFC tags optimally at a $\mathbf{1}-\mathbf{5} \mathrm{cm}$ distance and an optimal angle of 0 - -75 . The test results of the entire control system components can function properly and run as expected.

Keywords: Arduino, Bluetooth, Door control, NFC, Smartphone. 


\section{Pendahuluan}

Pada kehiduapn sekarang ini smartphone menjadi salah satu kebutuhan yang tidak bisa dipisahkan dari aktifitas manusia. Penggunaan smartphone sudah menjadi barang yang terus menemani aktivitas manusia. smartphone sudah memudahkann manusia dalam segala aktivitasnya. Seperti smartphone dapat difungsikan sebagai asisten pribadi, alat bantu payment, ticketing, mengakses ruangan dengan perangkat elektronik dikantor dan dirumah. Smartphone sekarang ini dapat difungsikan sebagai kunci pada perangkat elektronika dengan cara memanfaatkan fitur yang ada dalam smartphone tersebut. Dengan dimanfaatkan sebagai kunci perangkat elektronik atau telekomunikasi dapat mengantisipasi kasus kejahatan seperti pencurian, penyusupan ataupun hak akses yang bebas yang kerap terjadi yang disebabkan oleh kelalaian manusia. Sistem kendali pintu perangkat telekomunikasi menggunakan smartphone menanfaatkan NFC. (Near Communication Field) [1]. Adapun perangkat telekomunikasi yang diamankan adalah perangkat MSAN yang berfungsi sebagai access gateway dan mengoptimalkan media akses pada sistem transmisi serat optik [2]. Begitu pentingnya fungsi perangkat MSAN pada dunia telekomunikasi terutama dibidang wireline, maka perlu dibuatkan suatu sistem kendali pintu pada perangkat telekomunikasi dengan menggunakan smartphone. Sistem kendali ini memberikan kemudahan dan kenyamanan bagi pengguna dalam melakukan tugasnya dibidang telekomunikasi. Sistem ini memberikan pengamanan yang efektif karena hanya pengguna khusus saja, yang dapat mengaksesnya menggunakan aplikasi yang ada pada smartphone android dan NFC. Dengan adanya sistem kendali perangkat telekomunikasi ini dapat menjaga perangkat telekomunikasi secara aman dan berada pada tempatnya. Sistem kendali pintu perangkat telekomunikasi ini merupakan suatu alternatif kemudahan bagi penggunanya dalam melakukan tugas dan kewajibanya, yaitu dengan sistem kendali tanpa memerlukan kunci fisik.

\section{KaJian Pustaka}

Pada penelitian sebelumnya yang dilakukan oleh devi anggraini dengan judul penelitiannya sistem pengaman pintu shelter BTS otomatis menggunakan password berbasis bluetooth dan Arduino Uno. Pada penelitiannya memanfaatkan motor DC dan bluetooth sebagai media pengamanan dan pintu otomatis [3]. Penelitian yang dilakukan Soraya qonnita aisyah dkk dengan penelitiannya yang berjudul "Perancangan dan Implementasi sistem akses kontrol pada pintu berbasis teknologi near field communication dengan mikrokontroller Arduino Uno" [4]. Pada Penelitian lain terkait Near Field Communication (NFC) untuk teknologi ticketing pada pesawat terbang. Pada penelitian ini memanfaatkan Near Field Communication (NFC) untuk ticketing pada pesawat terbang di bandara Internasional Yogyakarta [5]. Pemanfaatan NFC sangat berguna bagi pengguna atau layanan pesawat terbang yang ada di bandara Internasional Yogyakarta. Pemanfaatan Near Field Communication (NFC) juga dapat diaplikasikan pada lingkungan kampus, seperti pada lingkungan perpustakaan. Teknologi Near Field Communication (NFC) memberikan kemudahan dan kenyamanan bagi penggunanya. Penelitian yang memanfaatkan dilingkungan kampus sudah dilakukan oleh Doaa Abdel dkk[6]. Seperti dapat diketahui Teknologi NFC pada smartphone dapat beroperasi di dalam tiga mode berbeda, yaitu: mode reader/writer, mode peer-to-peer (P2P), dan mode Host-based Card Emulation (sistem operasi android 4.4). Masing-masing mode membutuhkan perangkat NFC menggunakan sebuah format data umum untuk dapat saling berkomunikasi [7].

Near Field Communication (NFC) merupakan teknologi yang memungkinkan perangkat untuk berkomunikasi dengan user lain pada jarak maksimum $20 \mathrm{~cm}$ atau kurang. Pada jaman sekarang ini, produsen ponsel, lembaga perbankan, dan penyedia jaringan seluler berupaya menerapkan teknologi ini. Dengan memanfaatkan Near Field Communication (NFC) pada ponsel cerdas dan perangkat genggam lainnya memungkinkan pengguna atau konsumen untuk dapat menggunakan layanan komersial dengan lebih mudah. Pada penelitiannya A chairunnas dan I abdurrasyid yang berjudul "Near field communication (NFC) model for arduino uno based security systems office system" memanfaatkan Near Field Communication (NFC) untuk security sistem dan memanfaatkan Arduino Uno sebagai pengendali utamanya. Pembacaan Near field communication (NFC) dilakukan dengan jarak kurang lebih $20 \mathrm{~cm}$. Pada penelitiannya menggunakan 2 (dua) Arduino Uno. Ardunino Uno yang berpasangan dengan NFC shield dapat difungsikan sebagai input dari smartphone NFC dan arduino yang lain dipasangkan dengan sensor PIR sebagai input dari gerakan atau sensor untuk mendeteksi pergerakan [8]. 


\section{METODE PENELITIAN}

\section{A. Blok Diagram Sistem}

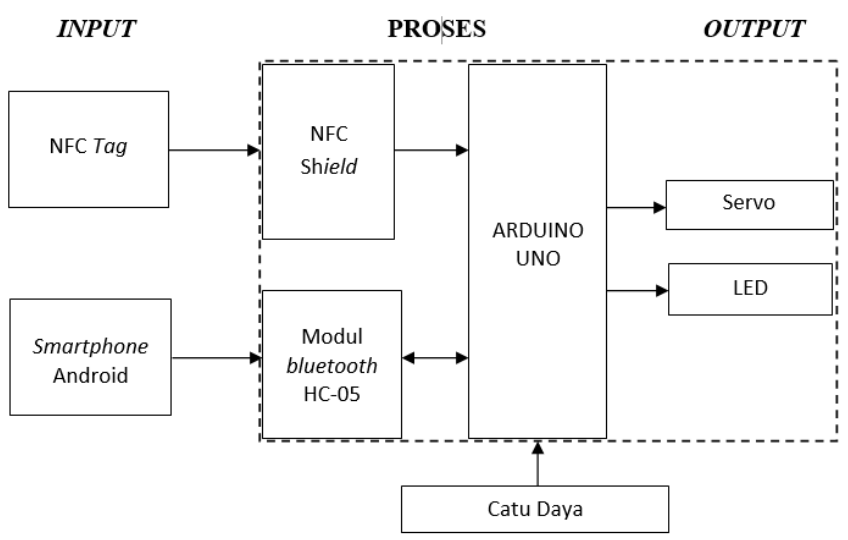

Gambar 1. Blok Diagram Sistem

Pada gambar diatas blok diagram terdiri dari input, proses dan output. Pada bagian input terdiri dari Near Field Communication Tag dan smartphone. Pada bagian proses terdiri dari Field Communication shield, modul bluetooth HC-05, mikropengendali Arduino Uno. Pada bagian output terdiri dari motor servo dan lampu indikator yang pasang LED. Catu daya sebagai pendukung utama dalam memberikan daya pada bagian proses dan output.

\section{B. Skema Rangkaian Sistem}

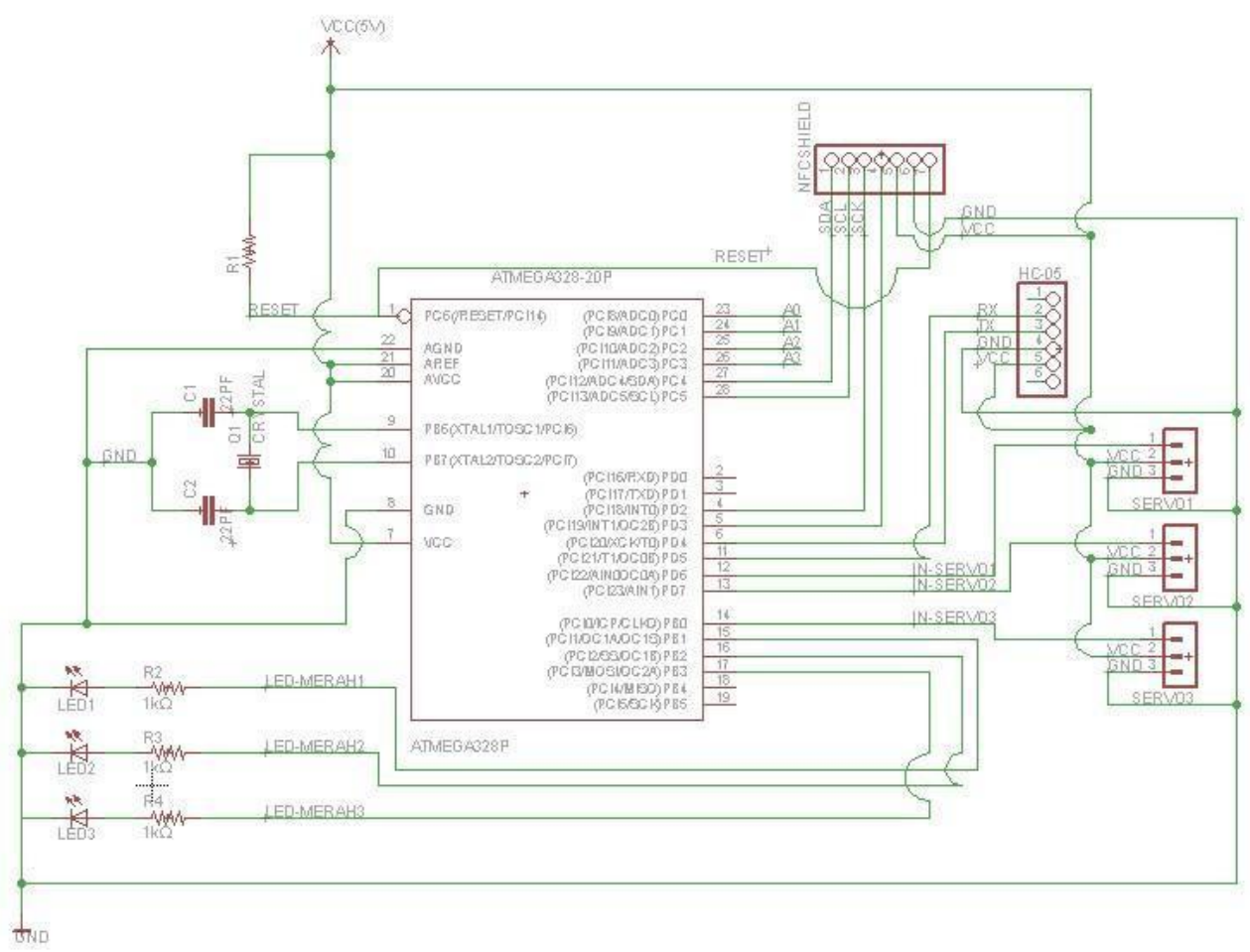

Gambar 2. Rangkaian Schematic Sistem Secara Keseluruhan 
Gambar diatas merupakan rangkaian schematic sistem, yang digambar menggunakan software aplikasi Eagle 7.1.0. Dengan menggunakan aplikasi Eagle 7.1.0 dapat merancang rangkaian schematic dari komponen utama hingga komponen - komponen pendukung lainnya. Pada rangkaian schematic ini menjabarkan dari tiap-tiap komponen, port - port yang digunakan. Rangkaian secara keseluruhan ini terdiri dari schematic pengendali Arduino UNO, rangkaian NFC Shield, Board untuk komponen bluetooth HC05, motor servo, dan rangkaian LED. Mikropengendali yang digunakan adalah Arduino UNO berfungsi sebagai sistem utama dari sistem kendali perangkat telekomunikasi ini. Sumber catu daya menggunakan USB interface pada mikropengendali Arduino yang berasal dari catu daya PLN. Pada sistem kendali ini modul bluetooth HC-05 mendapat sumbar daya dari Arduino. Setelah modul bluetooth HC-05 aktif dalam keadaan standby, selanjutnya smartphone user dihubungkan dengan modul bluetooth, apabila berhasil terhubung, kemudian membuka aplikasi kendali pada smartphone untuk memberikan perintah, namun sebelum masuk ke menu utama user perlu memasukkan password untuk melakukan kendali. Jika password benar maka Arduino akan mengeksusi program untuk menjalankan output. Begitu pula dengan NFC Shield, apabila tag yang di-scan terdapat informasi khusus maka Arduino akan mengeksekusi program agar output dapat berjalan. Dalam sistem kendali pintu perangkat telekomunikasi menggunakan smartphone berbasis Near Field Communication dengan bluetooth dan Arduino, fungsi dari bluetooth sebagai pembuka pintu. Sedangkan untuk NFC berfungsi untuk pengunci pintu. Output berupa motor servo difungsikan sebagai pengunci dan pembuka dari pintu perangkat telekomunikasi. Sedangkan untuk output LED warna merah yang masing - masing terhubung dengan resistor $1 \mathrm{k} \Omega$ menjadi indikator visual apabila pintu terbuka atau terkunci.

\section{Hasil dan Pembahasan}

Berikut hasil pengujian dari penelitian yang telah dilakukan. Pengujian awal dengan melakukan pengujian konektivitas bluetooth. Indikator teks "not connected" dengan warna teks merah yang terletak diatas menandakan kondisi ketika smartphone tidak terhubung/not connected dengan modul bluetooth. Untuk dapat terhubung dengan modul bluetooth dengan menekan gambar icon bluetooth pada menu utama.

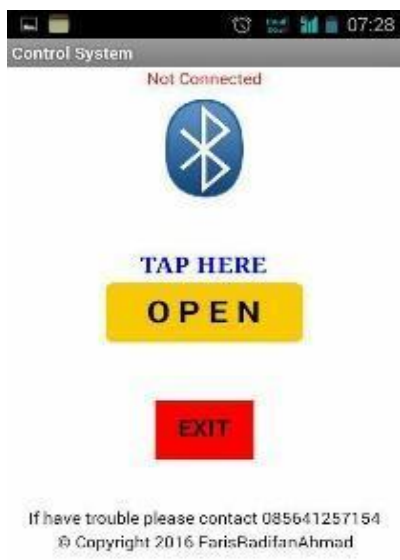

Gambar 3. Tampilan utama pada menu sistem kendali pintu

Agar dapat terhubung dan merubah teks indikator dari "not connected" menjadi "connected" dilakukan pemilihan koneksi dengan perangkat bluetooth dengan menekan icon bluetooth. Kemudian akan muncul daftar dari berbagai macam koneksi alamat dan nama koneksi bluetooth yang telah terhubung sebelumnya dengan smartphone, pilih alamat dan koneksi bluetooth HC-05. 


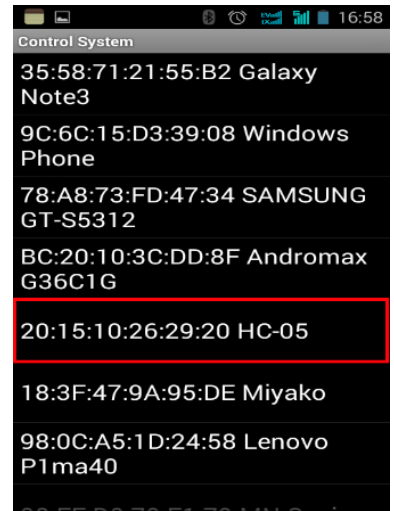

Gambar 4 Tampilan pemilihan bluetooth HC-05

Selanjutnya, apabila smartphone telah terhubung dengan modul bluetooth HC-05, maka indikator teks akan berubah menjadi "connected" dengan teks berwarna hijau dan dapat melakukan pengendalian. Berikut tampilan konektivitas smartphone sudah terhubung /connected dengan bluetooth.
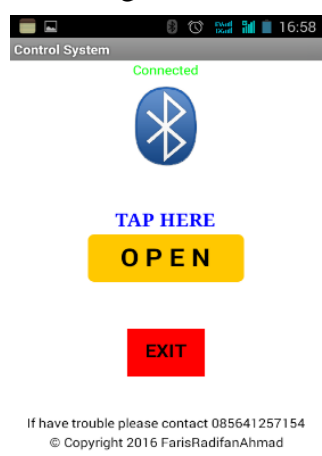

Gambar 5 Tampilan smartphone telah terhubung dengan bluetooth.

Pengujian ke 2 (dua) yaitu konektifitas Bluetooth dengan Arduino. Konektifitas komunikasi bluetooth merupakan akses awal untuk menjalankan sistem kendali ini. Tujuan dari tahap ini untuk mengetahui data yang dikirimkan melalui bluetooth dan jarak maksimum dalam melakukan komunikasi antara modul bluetooth HC-05 sebagai receiver dan smartphone sebagai transmitter ketika tanpa penghalang dan dengan penghalang. Berikut aktivitas pengukuran jarak konektivitas bluetooth tanpa penghalang.

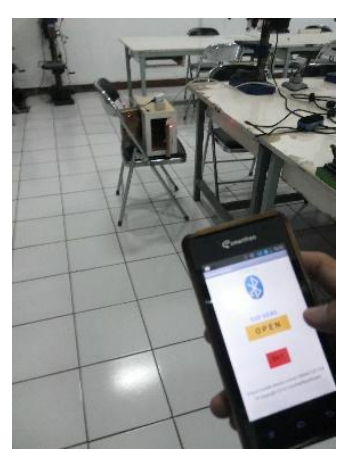

Gambar 6. Pengukuran jarak konektifitas bluetooth tanpa penghalang 
Tabel 1. Hasil pengujian jarak konektifitas bluetooth tanpa penghalang

\begin{tabular}{|c|c|c|}
\hline $\begin{array}{c}\mathbf{N} \\
\text { o }\end{array}$ & $\begin{array}{c}\text { Jarak } \\
\text { Pengujian }\end{array}$ & Konektifitas \\
\hline 1 & 2 meter & Terhubung \\
\hline 2 & 4 meter & Terhubung \\
\hline 3 & 6 meter & Terhubung \\
\hline 4 & 8 meter & Terhubung \\
\hline 5 & 10 meter & Terhubung \\
\hline 6 & 12 meter & Terhubung \\
\hline 7 & 14 meter & Terhubung \\
\hline 8 & 16 meter & Terhubung \\
\hline 9 & 18 meter & $\begin{array}{c}\text { Tidak } \\
\text { Terhubung }\end{array}$ \\
\hline
\end{tabular}

Jarak maksimum yang dapat dilakukan antara bluetooth smartphone dan modul bluetooth HC-05 agar terhubung tanpa adanya penghalang sejauh 16 meter. Berikut aktivitas pengukuran jarak konektifitas bluetooth dengan penghalang.

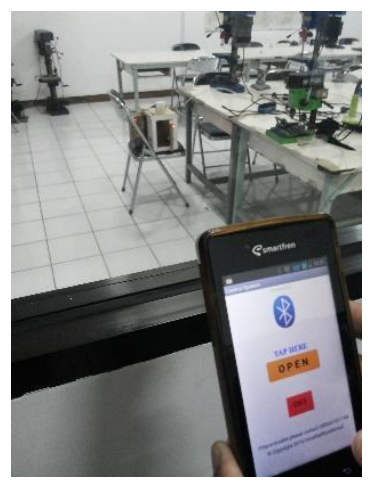

Gambar 7. Pengukuran jarak konektifitas bluetooth dengan penghalang

Tabel 2. Hasil pengujian jarak konektifitas bluetooth dengan penghalang

\begin{tabular}{|c|c|c|}
\hline $\begin{array}{c}\mathbf{N} \\
\text { o }\end{array}$ & $\begin{array}{c}\text { Jarak } \\
\text { Pengujian }\end{array}$ & Konektifitas \\
\hline 1 & 2 meter & Terhubung \\
\hline 2 & 4 meter & Terhubung \\
\hline 3 & 6 meter & Terhubung \\
\hline 4 & 8 meter & Terhubung \\
\hline 5 & 10 meter & $\begin{array}{c}\text { Tidak } \\
\text { Terhubung }\end{array}$ \\
\hline
\end{tabular}

Jarak maksimum antara bluetooth smartphone dengan modul bluetooth HC-05 dengan adanya penghalang terhubung sejauh 8 meter.

Selanjutnya melakukan pengujian pada NFC Tag Sticker. NFC Tag dapat difungsikan sebagai media masukan. Masukan dalam penelitian ini berupa akses untuk mengunci pintu dari perangkat telekomunikasi. NFC Tag yang digunakan merupakan jenis NFC type 2 atau NTAG203 dengan kapasitas memori 7kB. Berikut tampilan NFC tag sticker pada saat tidak terisi data dan sudah terisi data. 


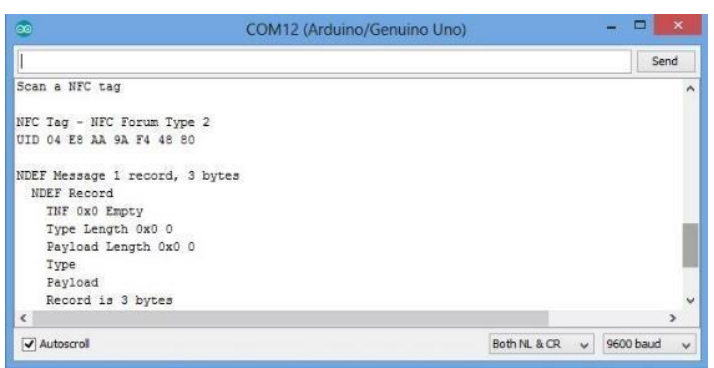

Gambar 8. Tampilan NFC tag sticker tidak terisi data

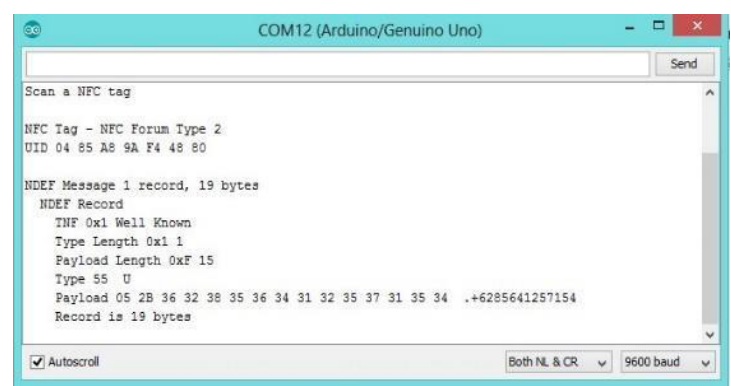

Gambar 9. Tampilan NFC tag sticker sudah terisi data

Selanjutnya pengujian sudut dan jarak pembacaan NFC Tag sticker. Berikut aktivitas pengujian pengukuran NFC tag sticker berdasarkan jarak.

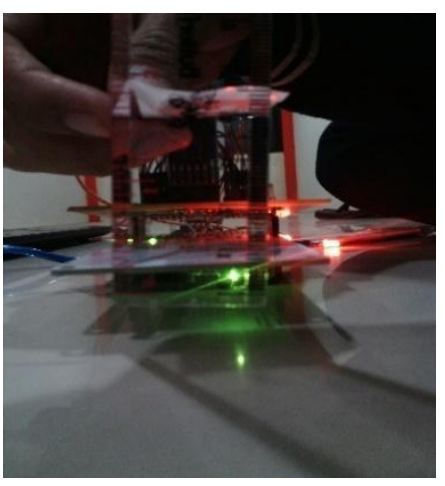

Gambar 10. Pengukuran NFC tag sticker berdasarkan jarak

Tabel 3. Hasil pengukuran NFC tag sticker berdasarkan jarak

\begin{tabular}{|c|c|c|c|}
\hline \multirow{2}{*}{ No } & \multicolumn{3}{|c|}{ Keberhasilan berdasarkan jarak } \\
\cline { 2 - 4 } & Jarak & Sukses & Gagal \\
\hline 1 & $1 \mathrm{~cm}$ & $10 \mathrm{x}$ & $0 \mathrm{x}$ \\
\hline 2 & $2 \mathrm{~cm}$ & $10 \mathrm{x}$ & $0 \mathrm{x}$ \\
\hline 3 & $3 \mathrm{~cm}$ & $10 \mathrm{x}$ & $0 \mathrm{x}$ \\
\hline 4 & $4 \mathrm{~cm}$ & $10 \mathrm{x}$ & $0 \mathrm{x}$ \\
\hline 5 & $5 \mathrm{~cm}$ & $3 \mathrm{x}$ & $7 \mathrm{x}$ \\
\hline 6 & $6 \mathrm{~cm}$ & $0 \mathrm{x}$ & $10 \mathrm{x}$ \\
\hline 7 & $7 \mathrm{~cm}$ & $0 \mathrm{x}$ & $10 \mathrm{x}$ \\
\hline 8 & $8 \mathrm{~cm}$ & $0 \mathrm{x}$ & $10 \mathrm{x}$ \\
\hline 9 & $9 \mathrm{~cm}$ & $0 \mathrm{x}$ & $10 \mathrm{x}$ \\
\hline 10 & $10 \mathrm{~cm}$ & $0 \mathrm{x}$ & $10 \mathrm{x}$ \\
\hline
\end{tabular}




\section{Keberhasilan Akses Mengunci}

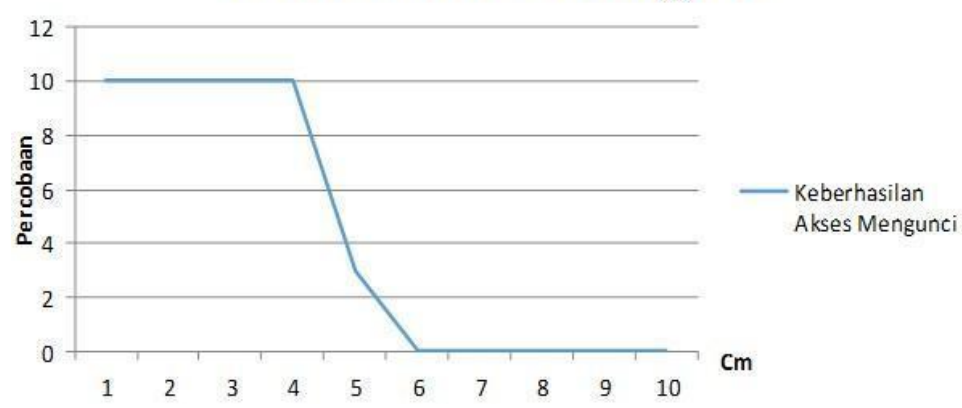

Gambar 11. Grafik pengukuran NFC tag sticker berdasarkan jarak

Dari grafik hasil pengukuran NFC tag sticker berdasarkan jarak dapat diketahui bahwa apabila jarak pembacaan jarak NFC tag semakin jauh maka tingkat keberhasilan dalam melakukan akses penguncian pintu akan semakin kecil. Selanjutnya dilakukan pengujian pegukuran NFC tag sticker berdasarkan sudut. Berikut aktivitas pegukuran NFC tag sticker berdasarkan sudut.

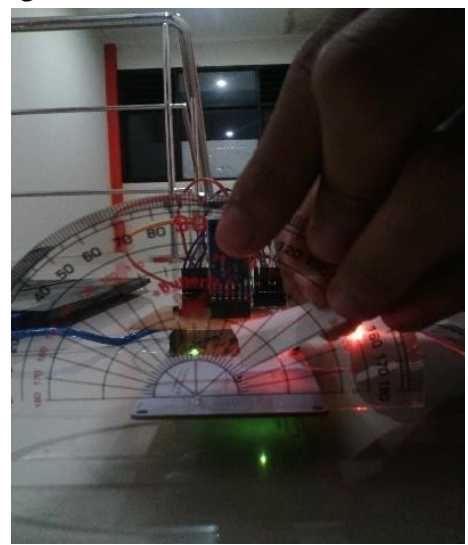

Gambar 12. Pegukuran NFC tag sticker berdasarkan sudut

Tabel 4. Hasil Pegukuran NFC tag sticker berdasarkan sudut

\begin{tabular}{|c|c|c|}
\hline \multicolumn{3}{|c|}{$\begin{array}{c}\text { Keberhasilan akses kendali kunci } \\
\text { pintu berdasarkan sudut }\left(^{(}\right)\end{array}$} \\
\hline Sudut & Sukses & Gagal \\
\hline $0^{\circ}$ & $10 \mathrm{x}$ & $0 \mathrm{x}$ \\
\hline $15^{\circ}$ & $10 \mathrm{x}$ & $0 \mathrm{x}$ \\
\hline $30^{\circ}$ & $10 \mathrm{x}$ & $0 \mathrm{x}$ \\
\hline $45^{\circ}$ & $6 \mathrm{x}$ & $4 \mathrm{x}$ \\
\hline $60^{\circ}$ & $4 \mathrm{x}$ & $6 \mathrm{x}$ \\
\hline $75^{\circ}$ & $1 \mathrm{x}$ & $9 \mathrm{x}$ \\
\hline $90^{\circ}$ & $0 \mathrm{x}$ & $10 \mathrm{x}$ \\
\hline
\end{tabular}




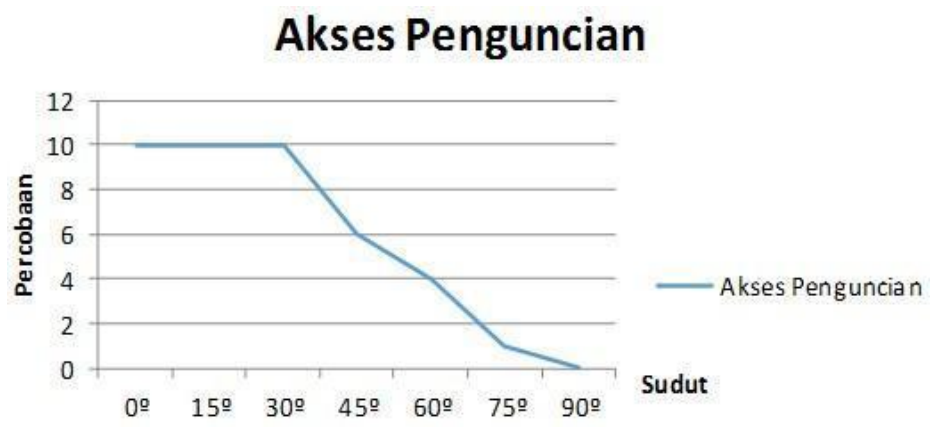

Gambar 13. Grafik pengukuran NFC tag sticker berdasarkan sudut

Setelah tahapan penelitian telah selesai dilakukan, aplikasi yang ada pada smartphone berjalan dengan baik tanpa adaya kendala yang berarti. Dengan memasukkan user name dan password yang telah diatur. Kemudian tombol untuk mengakses ke menu utama, tombol untuk melakukan pengendalian serta tombol untuk memutuskan hubungan dan mengeluarkan aplikasi tidak terdapat bug atau kesalahan. Berikutnya smartphone dapat terhubung dengan modul bluetooth HC-05. Dalam melakukan pengendalian jarak konektifitas bluetooth memiliki jarak ideal,jika dilakukan pengujian jarak konektifitas jarak ideal 16 meter. Jika dilakukan pengujian konektifitas jarak tanpa penghalang hanya mencapai jarak 8 meter. Sistem kendali pintu perangkat telekomunikasi tool yang digunakan NFC tag sticker yang memiliki kriteria khusus. Pembacaan NFC tag sticker memiliki jarak dan sudut ideal yang digunakan antara lain berjarak $1 \mathrm{~cm}-5$ cm dan dengan sudut $0^{\circ}-75^{\circ}$.

Dari hasil percobaan dan pengujian yang telah dilakukan menunjukkan bahwa setiap komponen dalam sistem kendali pintu perangkat telekomunikasi sudah bekerja dengan cukup baik. Jika bandingkan dengan menggunakan kunci manual, sistem kendali pintu perangkat telekomunikasi menggunakan smartphone dapat dilakukan dengan pengendalian dari jarak jauh. Dengan aplikasi yang telah dibuat dan ditanamkan pada smartphone memberikan kenyamanan dan keamanan terhadap pengguna sistem kendali perangkat telekomunikasi ini. Penggunaannya sistem kendali ini masih mempunyai kekeurangan, diantaranya belum dilengkapi fitur lupa password dan ganti password untuk mengaksesnya. Pengendalian dalam membuka dan mengunci masih dilakukan secara bersamaan, sehingga masih perlu pengendalian satu per satu untuk tiap pintu yang ada pada perangkat telekomunikasi agar lebih terkendali dengan lebih baik oleh pengguna dalam melakukan tugasnya. Penggunaan komunikasi yang terpisah antara bluetooth dan NFC tidak efektif dalam estimasi waktu penggunaan. Untuk mempermudah dan mempersingkat waktu penggunaan dalam melakukan pengendalian, dapat digunakan smartphone dengan fitur Near Field Communication (NFC) yang telah terintegrasi dengan mikropengendali Arduino.

\section{KESIMPULAN}

Dari penelitian yang telah dilakukan dapat diambil kesimpulan yaitu perancangan sistem kendali pintu perangkat telekomunikasi dapat diimplementasikan dengan sebuah protoype dengan 3 buah pintu yang terdiri dari motor servo dan LED di setiap pintu. Rangkaian motor servo pada pintu perangkat telekomunikasi bergerak dari posisi sudut $0^{\circ}$ ke sudut $90^{\circ}$ pada posisi membuka pintu dan bergerak dari posisi sudut $90^{\circ} \mathrm{ke} 0^{\circ}$ pada posisi mengunci pintu. Jarak komunikasi antara smartphone dan modul bluetooth HC-05 tanpa penghalang maksimal 16 meter dan dengan penghalang maksimal 8 meter untuk akses membuka pintu. Jarak dan sudut yang ideal dalam pembacaan NFC tag sticker untuk akses mengunci pintu dengan jarak $1 \mathrm{~cm}-5 \mathrm{~cm}$ dan sudut $0^{\circ}-75^{\circ}$.

\section{ACKNOWLEDGEMEN}

Penulis mengucapkan terima kasih kepada Tim pengelola Journal of Telecommunication, Electronics, and Control Engineering (JTECE), yang telah memberikan kesempatan untuk dapat mempublikasikan penelitian ini. Penulis juga berterima kasih kepada seluruh civitas Institut Teknologi Telkom Purwokerto yang telah mendukung dalam menyelesaikan penelitian ini. 


\section{REFERENCE}

[1] T. Igoe, D. Coleman, and B. Jepson, Beginning NFC: Near Field Communication with Arduino, Android, and PhoneGap. O'Reilly Media, 2014

[2] P. T. INDONESIA, "Dasar Sistem Komunikasi Optik-OPTICAL ACCESS NETWORK," Bandung: PT TELEKOMUNIKASI INDONESIA, Tbk TELKOMRisTI (R \& D Center), 2004.

[3] D. Anggraini, "Sistem pengaman pintu shelter BTS otomatis menggunakan password berbasis bluetooth dan Arduino Uno.," STT Telematika Telkom Purwokerto, 2015.

[4] S. Q. Aisyah, S. M. Nasution, A. N. Jati, F. T. Elektro, and U. Telkom, "Perancangan dan Implementasi sistem akses kontrol pada pintu berbasis teknologi near field communication dengan mikrokontroller Arduino Uno," vol. 2, no. 2, pp. 3436-3441, 2015.

[5] U. K. M. Bangi and S. D. Ehsan, "Application of Near Field Communication Technology for Mobile Airline Ticketing Wayan Suparta Institute of Space Science ( ANGKASA ), Universiti Kebangsaan Malaysia,” vol. 8, no. 8, pp. 1235-1243, 2012.

[6] I. S. December, T. Author, A. R. Reserved, and P. D. Doi, "Near-Field Communication Technology and Its Impact in Smart University and Digital Library : Comprehensive Study," vol. 3, no. 2, pp. 43-77, 2015.

[7] K. Curran, A. Millar, C. M. Garvey, and K. Curran, "Near Field Communication," vol. 2, no. 3, pp. 371-382, 2012.

[8] A. Syaputra and A. B. Pantjawati, "Near field communication ( NFC ) model for arduino uno based security systems office system Near field communication ( NFC ) model for arduino uno based security systems office system," 2018, pp. 1-11. 